\title{
Assessing the Role of the Framework Programmes for Research and Innovation 'Horizon 2020' and 'Horizon Europe' in Sustainable Development of the European Union
}

\author{
Elena Rodionova*, Zhanna Kuzminykh, and Ekaterina Gamova \\ Volga State University of Technology, Lenin Sq., 3, 424000Yoshkar-Ola, Russia
}

\begin{abstract}
The authors present the results of their research into the European Union's innovation policy and the framework programmes for research and innovation as a key tool for ensuring sustainable development in Europe. The study has found that the EU innovation policy has a strong focus on achieving the goals of the economic, social and environmentaldimensions of the sustainable development agenda. Besides, attaining certain innovation indicators itself is a target of sustainable development.The current Horizon 2020Programme and the future Horizon Europe Programme are clearly aligned with the EU's sustainable development strategic documents. As one of the leaders in the practical implementation of this concept, the European Union is setting standards and directions for further action for other countries and regions while remaining open to cooperative research and projects.
\end{abstract}

\section{Introduction}

The aggravation of first environmental and then socio-economic problems caused by the intensive development of industry, transport, construction and other sectors for attaining the goals of economic growth in the second half of the 20th century, has raised public awareness of the threat to the stability of the Earth's ecosystem function and humankind existence. The multidisciplinary concept of sustainable development, first defined in the scientific literature in the 1980 s, became a response to the global challenges.

Following the report Our Common Future released in 1987 by the World Commission on Environment and Development (WCED), the concept was widely disseminated and interpreted as 'development, meeting the needs of the present without compromising the ability of future generations to meet their own needs' [1].In its current meaning, the term sustainable developmentis used to describe a socially responsible, economically realistic and environmentally friendly process of development. Economic actorsare now expectedto give their fullest and continued attention to their environmental performance alongside their underlying moral and ethical principles[2].

\footnotetext{
*Corresponding author: rodionovaev@volgatech.net
} 
In 2015, seventeen Sustainable Development Goals (SDGs) were articulated in the United Nations (UN) document Transforming our world: The 2030 Agenda for Sustainable Development [3].

The European Union (EU) was one of the first regions in the world to put the ideas of sustainable development into practice. Already in 1997, the goal of achieving sustainable development was included in the Treaty of Amsterdam amending the Treaty on European Union. The first European Union Strategy for Sustainable Developmentwas adopted at the EU Summit in 2001.

In June 2006, a revised EU Sustainable DevelopmentStrategy was adopted.In line with the document, all the EU member states had to develop strategies for sustainable development by 2007. The task was accomplished.

The approach to planning sustainable development in Europe slightly changed in 2010, when the document A European Strategy for Smart, Sustainable and Inclusive Growth was developed to present the vision of a sustainable EU in a sustainable world and policy proposals in regard to the targets of Sustainable Consumption and Production, Society and Civic Participation: Investing in Research and Innovation, People and Human Talents, Employability and Social Inclusion, Energy and Climate Policy, Food, Farming and LandUse, Cohesion Policy [4].

In 2016, the European Commission developed the European Action for Sustainability, in compliance with which the EU SDG Multi-stakeholder Platform was established in 2017; it was intended to support broad public discussions engaging all stakeholders. In April 2019, another EU strategic document A Sustainable Europe by 2030 was adopted which is being extensively debated.

The EUconsiders innovation to be the crucial way to achieve the UN SDGs [5]. However, most of the EU countries are not among the world innovation leaders and lag behind their main competitors, Japan and the USA,with regard to a number of key innovation indicators. Consequently, the EU's main efforts in science and innovation are channeledtowards the generation, transfer and application of breakthrough innovations that would hold significant potential from the point of view of competitiveness in the new markets. The so-called 'social innovations', i.e. those having socially-oriented goals and means, have recently gained special attention in the EU [6]. It is noteworthythat the EU is committed to science and technology cooperation outside its borders. However, the EU is not seeking an exclusive position of a donor of technologies and knowledge for sustainable development; it is rather aiming at cooperative research and capacity building [7].

\section{Materials and Methods}

Our study aimed to comprehensively investigate the current and upcoming EU's framework programmes for research and innovation, identify their specific features and role in ensuring sustainable development in Europe. To achieve the purpose of the study, we used general and specific methods of scientific research. Theunderlying principles of the study included that of dialectics as a scientific approach considering the objects under investigation in their holistic universal interconnection and interdependence: a specific and comprehensive examination of phenomena; historicism; objectivity; consistency. For conducting the research within the framework based on the systematic approach to studying socio-economic phenomena, we used the abstract and logical, historical, and economic and statistical methods. The selection of research methods and techniques was determined by the principle of necessity and sufficiency in order to achieve the study objectives and ensure an in-depth and detailed examination of the key aspects of the research goals, as well as the reliability of results obtained. 
The research materials included the main strategic and policy documents on sustainable development and innovation adopted in the EU, the Sustainable Development Report by Sustainable Development Solutions Network and Institute for European Environmental Policy, the official presentation of the Horizon Europe programme, as well as research publications in the study area.

\section{Results and Discussion}

The EU's innovation policy is shaped both at the regional level and that of individual countries, and is implemented through an array of strategies, programmes and plans.

In 1984,the first Framework Programme for Research and Technological Development to support and foster research in the European Research Area (ERA)was adopted. Since then, Framework Programmes have become the core instrument for carrying out the innovation policy at the supranational level, as well as for encouraging international collaborations in innovation. [8]. The first 1984-1987 Framework Programme had a budge tofEUR 3.8 billion. Each subsequent Framework Programme received increasing amounts of funding, which, by the Seventh Programme of 2007-2013, reached the level of EUR 50.5 billion [9].

The current Eighth Programme intended for the period 2014-2020 is called the Framework Programme for Research and Innovation 'Horizon 2020'. Its budget is EUR 78.6 billion. The core message of Horizon 2020 is stimulating the transfer of promising technologies and scientific developments that have been createdin laboratories and institutes, to the industrial,economic, and social domains. The programme supports funding of innovation projects at different stages of their implementation, from the research process to market-ready products.Apart from the Framework Programme, Horizon 2020encompasses the financial provision part, the Competitiveness and Innovation Programme - CIP, and the European Institute of Innovation and Technology - EIT. Taking into consideration the previous experience of European-wide project implementation, the developerssought to simplify the procedures of participation in the programme, as well as make them more consistent thus enhancing programme accessibility for universities, research organizations, small and medium-sizedbusinessesfromEUcountriesandbeyond[10].

To ensure its maximum impact, the programme funding is concentrated in the three main areas: Societal Challenges (EUR 29.7 billion), Excellent Science (EUR 24.4 billion), and Industrial Leadership (EUR 17.0 billion). In addition, funding is provided to the European Institute of Innovation and Technology (EUR 2.7 billion), Euratom (EUR 1.6 billion), and other areas (EUR 3.2 billion).

The "Societal Challenges" area is the one most closely associated with the SDGs and ideas; it is where research is funded in the following areas: Health, Demographic Change and Wellbeing is funded; Food Security, Sustainable Agriculture and Forestry, Marine, Maritime and Inland Water Research and the Bioeconomy; Secure, Clean and Efficient Energy; Smart, Green and Integrated Transport; Climate Action, Environment, Resource Efficiency and Raw Materials; Europe in a Changing World - Inclusive, Innovative and Reflective Societies; Secure Societies - Protecting Freedom and Security of Europe and its Citizens [10].

The interim evaluation of the Horizon 2020programmehas revealed a significant impact ofits agenda implementation. Horizon 2020 only accounts for 10 per cent of public funding of research and development in the EU;however, the macroeconomic and social impact of this investment was found to be very significant.About 83 per cent of the projects financed by the Horizon 2020programme could not have been developedwithout support at the EU level [11]. 
Currently, the Ninth Framework Programme for Research and Innovation - 'Horizon Europe' - is being developed forimplementation in the 2021-2027 time period. The strategic focus on breakthrough innovation, characteristic of Horizon 2020, will remain unchanged for Horizon Europe, which will build upon the lessons and evolutionary development of the existing approaches arising from the previous programme.

The budget of about EUR 100 billion is planned for the new programme in order to cover the following areas: Global Challenges and European Industrial Competitiveness (EUR 52.7 billion), Excellent Science (EUR 25.8 billion), Innovative Europe (EUR 13.5 billion), Euratom (EUR 2.4 billion), Widening Participation and Strengthening the European Research Area (EUR 2.1 billion).

The Horizon Europe programme aims to shape a sustainable, fair and successful future for our planet and its population. The official presentation of the programme emphasizes that it should help to achieve the seventeen UN SDGs [12]. While the Horizon 2020programme only partly focused on the technologies aimed at achieving the SDGs, the new Horizon Europe initiative is most closely related to them [5].

Another novelty of the programme is establishing the so-called "R\&I Missions", portfolios of actions across disciplines that aim to reach a challenging but measurable goal within set time limits, as well as make an influenceon the society and policy makingand have relevance for a significant part of the EU residents.Inthecourseofnegotiations and discussions on the preparation of the programme, five main missions were identified: Adaptation to climate change, including societal transformation, Cancer, Healthy oceans, seas, coastal and inland waters, Climate-neutral and smart cities, Soil health and food [12].

Thus, the European Union is currently making increased efforts to ensure that the innovation policy, implemented primarily through the framework programmes, becomes a driver for achieving the SDGs. Meanwhile, within the SDG 9 "Build resilient infrastructure, promote inclusive and sustainable industrialization, and foster innovation", the EU considers innovation in itself as one of the priority goals of the EU's policy. In the 2019 Europe Sustainable Development Report, innovative economy is considered to beone of the six major transformations needed for achieving the SDGs in the EU [5].

\section{Conclusion}

Innovation is widely recognized by the scientific and business community as a key driverof the economic growth.However, in the context of sustainable development, we observe focus shifts regarding the innovation goals andthe attitudes to the openness to the global community. This trend is most apparent in the EU's actiontowards the development and implementation of its innovation policy.

The innovation policy of the EU as a leader and standard setter in the area of sustainable development, has a pronounced focus on achieving its goals regardingthe economic, social, and environmental dimensions. On the other hand, the achievement of certain innovation activity indicators as such is a target of sustainable development. Thus, the EUcurrently approaches innovation from two different standpoints: firstly, as a way to achieve the Sustainable Development Goals facing the EU countries; secondly, as one of the goals of this development.

The main instruments of the EU innovation policy are itsframework programmes. There is a strong correlation between the current Horizon 2020Programme and the next Horizon EuropeProgramme with thestrategic documents in the area of sustainable development developed by the EU and its member states. The European Union as one of the leaders in sustainable development sets standards and directions for further action for other countries and regions, while remaining open to cooperative research and projects. 


\section{References}

1. World Commission on Environment and Development,Our Common Future (1987)

2. E.A. Tarkhanova, Terra Economicus, 2, 75(2018)

3. Transforming our world: the 2030 Agenda for Sustainable Development (2015), https://sustainabledevelopment.un.org/

4. Contribution of the SDG Multi-Stakeholder Platform to the Reflection Paper "Towards a sustainable Europe by 2030" (2018), https://ec.europa.eu/

5. The 2019 European Sustainable Development Report. Paris and Brussels: SDSN \& IEEP (2019)

6. A. Schröder, M. Menapace, A. Shabunova, Economic and Social Changes: Facts, Trends, Forecast, 1, 216 (2018)

7. M.V. Shugurov, Legal Concept, 2, 139 (2019)

8. K.A. Ibragimova, Observer, 11, 51 (2017)

9. European Commission proposes $€ 100 \mathrm{~B}$ for research programme (2018), https://sciencebusiness.net/

10. Horizon 2020. EU Research and Innovation Framework. A practical guide for researchers from Russia(2014), http://ncp.tsagi.ru/

11. N.V. Gaponenko, V.S. Ustenko, Systems and Management, 3, 6 (2019)

12. Horizon Europe. Investing to shape our future (2019), https://ec.europa.eu/ 